\title{
Nurse home visits to low income, first time mothers reduced pregnancy induced hypertension and childhood injuries
}

\author{
Kitzman H, Olds DL, Henderson CR, et al. Effect of prenatal and infancy home visitation by nurses on pregnancy outcomes, \\ childhood injuries, and repeated childbearing. A randomized controlled trial. JAMA 1997 Aug 27;278:644-52.
}

\section{Question}

Do prenatal and postnatal home visits by nurses improve maternal and child outcomes?

\section{Design}

Randomised controlled trial with $\leqslant 2$ years follow up.

\section{Setting}

Public obstetrics clinic in Memphis, Tennessee, USA.

\section{Participants}

1139 women (mean age 18 y, 92\% African-American) who were $<29$ weeks gestation, had no previous live births, no chronic illnesses, and $\geqslant 2$ sociodemographic risk factors (unmarried, $<12$ y education, and unemployed). Most were unmarried (98\%), $\leqslant 18$ years $(64 \%)$, and had incomes at or below poverty guidelines $(85 \%)$.

\section{Intervention}

Stratified by maternal race, age, gestational age, employment status, and geographic region, women were allocated to 1 of 4 treatment groups: (1) transportation to prenatal care $(\mathrm{n}=166)$; (2) treatment 1 plus developmental screening at 6,12 , and 24 months $(\mathrm{n}=515)$; (3) treatment 2 plus prenatal nurse home visits (mean 7 visits) $(\mathrm{n}=230)$; or $(4)$ treatment 3 plus 2 years of postpartum home visits (mean 26 visits) $(\mathrm{n}=228)$. Groups 2 and 4 were followed up for 2 years $(90 \%$ follow up based on completed office assessments); groups 1 and 3 were followed up until delivery ( $95 \%$ follow up based on newborn infants' records abstracted).

\section{Main outcome measures}

Pregnancy induced hypertension; preterm delivery; low birth weight; subsequent pregnancies; mothers' child rearing beliefs, education, and employment; quality of the home environment; children's healthcare encounters for injuries or ingestions (ie, eating potentially harmful substances); immunisation status; mental development; and behavioural problems.

\section{Main results}

Fewer women who received prenatal visits (groups 3 and 4) had pregnancy induced hypertension than those not visited (groups 1 and 2) $(13 \% v 20 \%, \mathrm{p}=0.009)$. No differences were found for preterm deliveries or low birthweight infants.

At 2 years, women visited by nurses (group 4) had fewer second pregnancies $(36 \% v 47 \%, \mathrm{p}=0.006)$, held fewer child rearing beliefs associated with abuse and neglect $(\mathrm{p}=0.003)$, and had homes that were more emotionally and cognitively stimulating $(p=0.003)$ than those not visited (group 2$)$. The groups did not differ for mother's education or employment.

Children who received home visits (group 4) had fewer healthcare encounters for injuries or ingestions (43\% v 56\%, $\mathrm{p}=0.05$ ) than children who did not (group 2), but did not differ for immunisation status, mental development, or behaviour problems.

\section{Conclusions}

Prenatal home visits reduced pregnancy induced hypertension in young women with low incomes. Prenatal and postnatal home visits reduced subsequent pregnancies and children's healthcare encounters for injuries and ingestions.

Sources of funding: National Institute of Nursing Research; Bureau of Maternal and Child Health; Administration for Children and Families; Office of the Assistant Secretary for Planning and Evaluation; National Center for Child Abuse and Neglect; Robert Wood Johnson Foundation; Carnegie Corporation; Pew Charitable Trusts; William T Grant Foundation.

For article reprint: Dr D L Olds, University of Colorado Health Sciences Center, 1825 Main Street, Denver, CO 80218, USA. Fax +1 3038645236.

A modified version of this abstract appears in Evidence-Based Mental Health 1998 May and Evidence-Based Medicine 1998 May-June.

\section{Commentary}

These 2 excellent trials by Kitzman et al and Olds et al add strength to the large, often poor quality, studies on home visiting with pregnant women and young families. The replication of Olds' 1970s home visiting trial by Kitzman et al shows that such programmes are successful with disadvantaged groups and can be successfully administered in a public health setting. The 15 year follow up by Olds et al provides new information about the effects on women, families, and society.

Kitzman et al confirm that prenatal home visits by nurses can improve the health of pregnant women. The failure to improve birth weight is consistent with previous studies, ${ }^{1}$ as is the lack of change in preterm births, which is probably explained by racial differences in risk profiles and greater surveillance of intervention groups. ${ }^{2}$ Nevertheless, the improvements in maternal hypertension and kidney infection are important, independent of effects on fetal health.

The study by Kitzman et al confirms the effects of postnatal visits on child health and parenting, ${ }^{3}$ in particular, the contribution of home visits to childhood injury prevention. ${ }^{4}$ The study by Olds $e t$ al fills a gap in earlier research by including outcomes for women as well as children. A change in outcomes such as verified cases of child abuse and criminal behaviour is noteworthy. However, Kitzman et al did not show short term effects on maternal education and employment. These outcomes are difficult to change, and long term follow up will be important.

These 2 studies overcame many problems common to community research. They had high participation and follow up rates, concealed and random allocation, well designed and blinded outcome measurement, and clear theoretical foundations. The subgroup analysis by Olds $e t$ al of low income, unmarried women was not initially part of the design and should be interpreted with care. However, Kitzman et al improved on the initial trial by increasing the sample size, adding 3 important factors to stratification and hypothesising a greater effect on women with few psychological resources. (commentary continued on p 77) 


\section{Nurse home visits reduced child abuse and neglect over a 15 year period}

Olds DL, Eckenrode J, Henderson CR, et al. Long-term effects of home visitation on maternal life course and child abuse and neglect. Fifteen-year follow-up of a randomized trial.JAMA 1997 Aug 27;278:637-43.

\section{Question}

Do prenatal and postnatal home visits by nurses have long term effects on maternal life course and child abuse and neglect?

\section{Design}

Randomised controlled trial with 15 years follow up.

\section{Setting}

Public antenatal clinic and private obstetrics offices in a semirural area of central New York State, USA.

\section{Participants}

400 women (11\% African-American) who were $<25$ weeks gestation, had no previous live births, and had $\geqslant 1$ sociodemographic risk factor $(<19 \mathrm{y}$, unmarried, or low socioeconomic status). Most were unmarried $(62 \%), \geqslant 19$ years $(52 \%)$, and had low socioeconomic status (59\%). Follow up was $81 \%$.

\section{Intervention}

Stratified by maternal race, marital status, and geographic region, women were allocated to 1 of 4 treatment groups: (1) sensory and developmental screening for children at 12 and 24 months $(\mathrm{n}=94)$; (2) treatment 1 plus free transportation to prenatal and child health care until the child's second birthday $(\mathrm{n}=90)$; (3) treatment 2 plus prenatal nurse home visits (mean 9 visits) $(\mathrm{n}=100)$; and $(4)$ treatment 3 plus home visits (mean 23 visits) for 2 years after delivery $(n=116)$.

\section{Main outcome measures}

Substantiated reports of child abuse or neglect, subsequent births, duration of welfare benefits, and mothers' substance abuse, arrests, and convictions.

\section{Main results}

Analysis was by intention to treat, and adjusted for sociodemographic variables. Women who received home visits until 2 years after delivery (group 4) were compared with women who did not (groups 1 and 2). Nurse home visits reduced state verified cases of child abuse and neglect (log incidence difference $0.77, \mathrm{p}<0.001)$. No differences were found for subsequent births; months that women received welfare; behavioural impairment because of substance abuse; arrests; or convictions. Subgroup analysis of women who were unmarried and from low socioeconomic status households $(40 \%)$ showed that home visits reduced child abuse and neglect (log incidence difference 1.61, $\mathrm{p}<0.001$ ), subsequent births (mean difference 0.5 births, $\mathrm{p}=0.02$ ), months that women received welfare (mean difference 29.9 mo, $p=0.005)$, behavioural impairment because of substance abuse (log incidence difference 0.58, $\mathrm{p}=0.005$ ), arrests $(\log$ incidence difference $1.74, \mathrm{p}<0.001)$, and convictions (log incidence difference 1.65, $\mathrm{p}<0.001$ ).

\section{Conclusions}

Prenatal and postnatal home visits by nurses reduced the incidence of child abuse and neglect over a 15 year period. Home visits to unmarried women from low socioeconomic households also reduced subsequent births, use of welfare, substance abuse, arrests, and convictions.

Sources of funding: National Institute of Mental Health and US Department of Health and Human Services.

For article reprint: Dr D L Olds, University of Colorado Health Sciences Center, 1825 Main Street, Denver, CO 80218, USA. Fax +1 3038645236.

A modified version of this abstract appears in Evidence-Based Mental Health 1998 May and Evidence-Based Medicine 1998 May-Jun. (commentary continued from page 76 )

These 2 studies strengthen the conclusion that teaching, counselling, family support, and referral services provided by nurses to first time mothers in their homes change serious short and long term outcomes. Programmes which offer a similar integrated service, with adequate contact time by well trained nurses, who individualise the intervention and address the full context of women's lives, are likely to change the prospects of disadvantaged young women and children. These results, however, cannot be generalised to other programme designs.

Managers need to scrutinise home visiting programmes in light of those proved to be effective, looking at theoretical linkages, risk factors, and the specific quality and quantity of service. Nurses providing home visits must examine the content of their interventions, incorporate the full range of educational and supportive elements, and continue visits throughout infancy.

This research reinforces the importance of adequate funding for home visiting for mothers with few resources. The public health significance of the changes in the intervention group in the study by Olds $e t$ al should not be ignored: every third woman chose to limit her family by 1 child and every family received welfare for 1 year less. Although the changes were not statistically significant for the total sample, at a population level such changes would be enormous.
Sarah Hayward RN, MPH Consultant, Infoward Inc Edmonton, Alberta, Canada

1 Hodnett ED. Support from caregivers during at-risk pregnancy. In: Cochrane Database of Systematic Reviews. The Cochrane Library. Oxford: Update Software, 1998.

2 Hueston WJ, Knox MA, Eilers G, et al. The effectiveness of preterm-birth prevention educational programs for high-risk women: a meta-analysis. Obstet Gynecol 1995;86:705-12.

3 Ciliska D, Hayward S, Thomas H, et al. A systematic overview of the effectiveness of hys visiting as a delivery strategy for public home visiting as a delivery strategy for public Health 1996;87:193-8. Realth 1996,87.193-8.

Roberts I, Kramer MS, Suissa S. Does home visiting prevent childhood injury? A systematic review of randomised controlled trials. BMJ 1996;312:29-33

5 MacMillan HL, MacMillan JH, Offord DR. Primary prevention of child maltreatment. In: Canadian Task Force on the Periodic Health Examination. Canadian guide to clinical preventive health care. Ottawa: Health Canada, 1994; 320-32. 